\title{
Data Intelligent Analysis for Decision-Making at Universities
}

\author{
Latifa Oubedda $^{1}$, Brahim Erraha ${ }^{1} \&$ Mohamed Khalfaoui ${ }^{2}$ \\ ${ }^{1}$ National School of Applied Sciences, University Ibn Zohr, Agadir, Morocco \\ ${ }^{2}$ Superior School of Technology SALE, University Mohammed V Agdal, Rabat, Morocco \\ Correspondence: Latifa Oubedda, Laboratory of Industrial Engineering and Computer Science (LG2I), National \\ School of Applied Sciences, University Ibn Zohr, Agadir, Morocco. E-mail: 1.oubedda@gmail.com
}

Received: March 5, 2012 Accepted: March 20, 2012 Online Published: June 1, 2012

doi:10.5539/cis.v5n4p61 URL: http://dx.doi.org/10.5539/cis.v5n4p61

\begin{abstract}
The objective of this work is to develop a decisional information system for the operation of a model consisting of key stakeholders of the university (teachers, students and administrative). This system is based on the relationship between actors and their activities and their aggregations in a graduate level. It aims to make available to managers of the university a set of dashboards that can improve the quality of education provided. We begin by modeling the actors up and study processes on their own organizations, their activities and their aggregations. We try to answer the question: how to reproduce a set of metadata specific to multidimensional databases specific to universities based on the decision.
\end{abstract}

Keywords: multidimensional databases, metadata, data marts, design and information system

\section{Introduction}

In this paper, we seek to provide an answer to the following question: how does the contribution of modeling allows players to bring an information system to the level of intelligence information system (Ann, 2000) by the establishment of a university warehouse? We approach the modeling of actors with respect to a university information system. This allows changing and improving an academic information system into a university strategic information system.

At the outset, we provide a succinct overview of our problematic. We then proceed to developing our proposed contributions with respect to two specific points: namely how certain steps led us to reason by urbanization levels for a system of academic information and how to think a model of the actor committing ourselves to processes specific to the administrative processes specific to the teacher and processes specific to the student in a university setting (Oubedda, Erraha, \& Khalfaoui, 2012a; Oubedda, Erraha, \& Khalfaoui, 2012b). We begin our study by modeling the university needs of actors (students, faculty and administrative). And we take into account the overall context of a university information system (large volume of unstructured information and not exploitabal). Therefore proposed to be a formal model allows to study the requirement of basic information, analyzing the information, tools of different choices decision support (SIAG).

That's why we use this model in an experiment which is in turn - used in the conclusions of the third part of this document. Then, we expose how the experience has improved our model to implement an application using an open source product (decision support software that we take as an example).

\section{Context}

Our objective is to enable university decision makers and managers to have valuable information which they can refer to and trust as part of their decision-making. That is why, it is necessary to produce pertinent and value-added information. This requirement must be reflected in the various phases of the process:

- Information gathering

-Treatment

- Transmission 


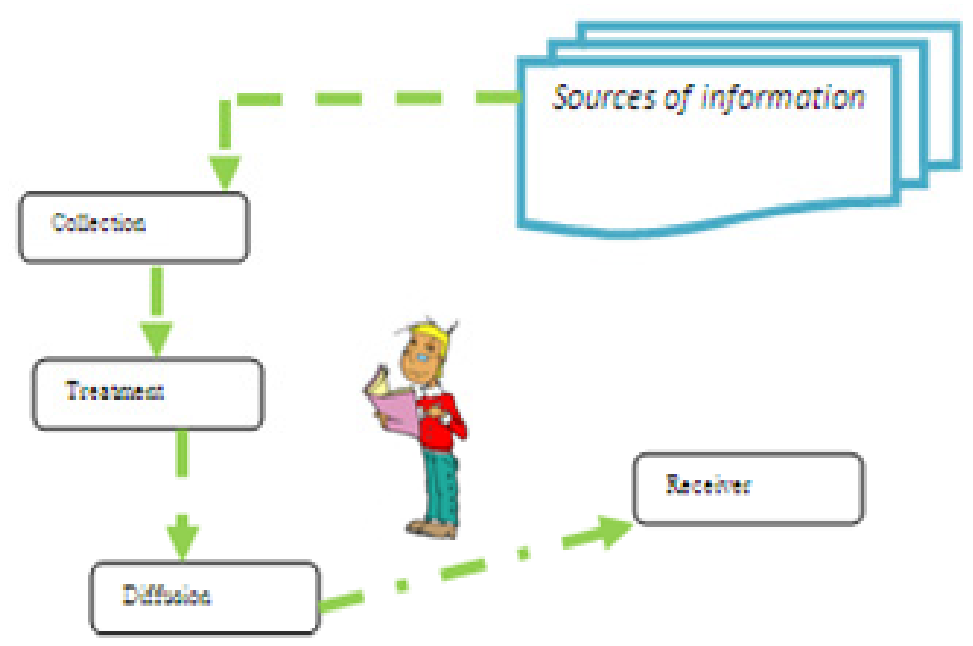

Figure 1. Saw what a difference can be made between a strategic intelligence and a decision maker in terms of information system

As we have already mentioned (especially in Figure 1), we now consider the difference that can be made between a strategic intelligence and a decision maker in terms of information system. A decision maker must include the development of parameters for calculating indicators and interpret the indicators. A strategic intelligence, or analyst, has more expertise in this domain of knowledge, identification of relevant sources, techniques for finding information, formatting information, validating information and calculation of the indicators. The Information Specialist has an intermediary role between the decision-making and the information requested and can be the designer of the university strategic information system.

Recall that Maslow's pyramid of needs consists of five levels (Figure 2). We seek first, according to Maslow, to meet every need of a given level before thinking about the needs of the next level. These categories of needs are, in ascending order: physiological, safety, love, belonging, esteem of others, self-esteem and personal fulfillment.

Depending on the model of Maslow's hierarchy adapted to the university information systems, the needs of information system users reverse the priorities:

1) The task of IT services is to execute, that is to say, manage and develop services.

2) The task of improving business, and the ratio efficiency / cost is to support, that is to say, to design and put into practice the applications and infrastructure.

3) The task of competitive advantages is to decide, that is to say, to plan developments in the IS needs and technologies.

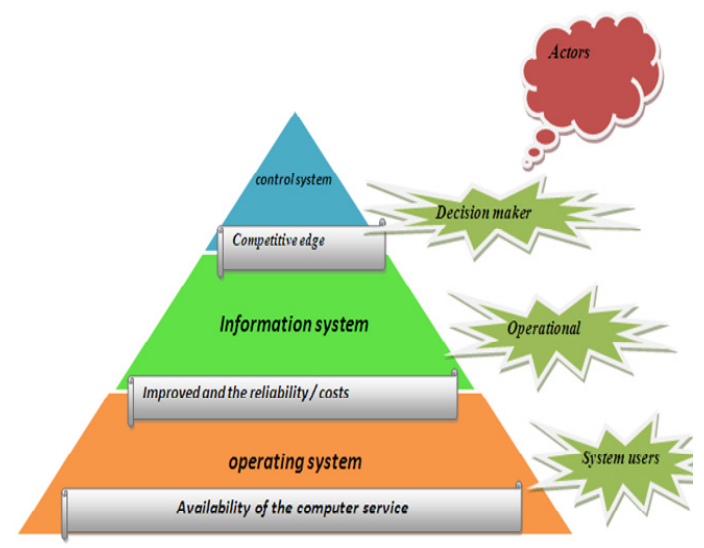

Figure 2. Location of intelligence information system and user-actor in the systemic structure of the university: Maslow's hierarchy of IS 


\subsection{The SIAG Model}

According to the SIAG model developed by our team, we observe several processes in the phenomenon of information retrieval. These are the focus of our reflections. The model represents a situation SIAG information retrieval that involves the following cognitive phases:

Discoing the world of information $\Rightarrow>$ Study

The basic information requirement $=>$ Item

The analysis of the basis of information $=>$ Resolution

Analysis based on different choices $=>$ Gloss

This model uses action verbs to describe different stages of information seeking: to investigate, item, analyze and gloss. These words evoke the underlying functionality of the information system (Olivier, 2007a; Olivier, 2007b) so as to satisfy the end user. We partially benefit from this model to analyze the situations of our various stakeholders (policy makers and institutions of the presidency of the university) in a research or production information.

\subsubsection{Implementation}

Given the scope of this university project which combines students, professors, administrative staff all of which improve and operate in various disciplines in terms of their thematic and structural information proposal, we base it on the model of a warehouse data, taking into account the different trades. For example a person may have different responsibilities: it can have the status of responsible teaching.

We discuss the data related to actors on different levels. We distinguish three levels: the actors' level, the administrative level and the educational level.

- The actors' level allows for an initial typology of actors - around 3 classes, showing students, teachers and administrators.

- The educational level is used to identify bases 'referents' correlated with previously identified actors: foundation courses geared towards the students, baselines for serving teachers and basic rules and regulations for the administration of destination (Peguiron, David, \& Thiery, 2003).

- The administrative level census data on the administrative situation of the student actor, data on the situation of the administrative actor and teacher data from administrative and financial management of students, teachers and training relevant to the administrative actor. We illustrate by a diagram data related to the actors, supplemented by what already existed. After the consolidation of the formula 1, we obtain: The portfolio of the source (S) defines all the activities to be performed during one cycle by each university players. Category (C) defines the three actors of the university: Student, Teacher, and Administrator. Aggregation (A) defines the needs of each player for a graduate level (Figure 3).

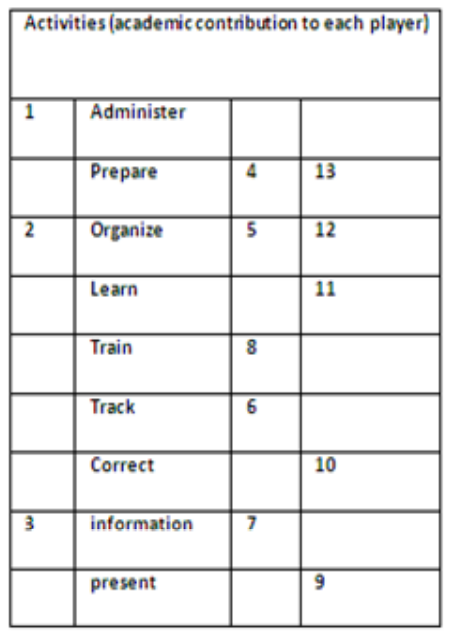

\begin{tabular}{|l|l|l|l|}
\hline $\begin{array}{l}\text { Aggregations (by contributing to university each } \\
\text { actor) }\end{array}$ & Regulation & 5 & 10 \\
\hline & Budget & 1 & \\
\hline & Monitoring & & 11 \\
\hline 15 & Training & & 8 \\
\hline 13 & Course & 6 & 9 \\
\hline & Registration & 2 & \\
\hline 12 & Census & 3 & 7 \\
\hline 14 & Preparation & 4 & \\
\hline & & & \\
\hline 16 & Resources & & \\
\hline
\end{tabular}

Figure 3. Defines all the activities to be performed during one cycle by each university players. Category (C) defines the three actors of the university: Student, Teacher, and Administrator 
Beginning with the University Cycle:

The administrative actors' portfolio is the first actor at a time $\mathrm{t}$ :

Administrative actor $(\mathrm{PA})=\{\mathrm{Ci}(1 \leq \mathrm{i} \leq 3) ; \mathrm{Aj}(1 \leq \mathrm{j} \leq 6)\}$

The Teacher actor portfolio is the second player at time $\mathrm{t}+\Delta \mathrm{t}$ :

Actor Teacher $(\mathrm{PE})=\{\mathrm{Ci}(3 \leq \mathrm{i} \leq 8) ; \mathrm{Aj}(6 \leq \mathrm{j} \leq 11)\}$

The Student actor portfolio is the No. 3 player at a time $t+\Delta t+1$ :

Actor Student $(\mathrm{PT})=\{\mathrm{Si}(8 \leq \mathrm{i} \leq 13) ; \mathrm{Aj}(11 \leq \mathrm{j} \leq 16)\}$

This model is then obtained (Figure 4)

$$
\operatorname{Actor}\left\{\sum_{i=1}^{i-13} S_{i} ; \sum_{j-1}^{j-16} A_{j}\right\}
$$

Figure 4. This model is then obtained in Beginning of the University Cycle

End of University Cycle: At the end of the cycle, the three actors are involved (Figure 5)

\begin{tabular}{|l|l|l|l|}
\hline \multicolumn{5}{|l|}{ Activit es (academic contribution to each player) } \\
\hline Review & 31 & & \\
\hline training & & 33 & \\
\hline course & & 35 & \\
\hline End Exhibit & & 34 & \\
\hline SID & & & 37 \\
\hline Preparation & 30 & 32 & 36 \\
\hline
\end{tabular}

\begin{tabular}{|l|l|l|l|}
\hline \multicolumn{4}{|l|}{ Agregations (by contrituting to university each actor) } \\
\hline Statistical & 42 & & \\
\hline Training & 41 & 44 & \\
\hline Diploma & & & 38 \\
\hline Course & & & 39 \\
\hline Certification & 40 & 43 & \\
\hline
\end{tabular}

Figure 5. End of University Cycle: At the end of the cycle, the three actors are involved

The Teacher actor portfolio is the first speaker at the end of the academic cycle:

$$
\text { Teacher Actor }(\mathrm{PE})=\{\mathrm{Si}(29 \leq \mathrm{i} \leq 31) ; \mathrm{Aj}(37 \leq \mathrm{j} \leq 39)\}
$$

The Student actor portfolio is the second place at the end of the academic cycle:

$$
\text { Student Actor }(\mathrm{PT})=\{\mathrm{Si}(31 \leq \mathrm{i} \leq 35) ; \mathrm{Aj}(42 \leq \mathrm{j} \leq 44)\}
$$

The administrative Actors portfolio is the last speaker at the end of the academic cycle:

$$
\text { Administrator Actor }(\mathrm{PA})=\{\mathrm{Si}(35 \leq \mathrm{i} \leq 37) ; \mathrm{Aj}(39 \leq \mathrm{j} \leq 42)\}
$$

The following model is then obtained (Figure 6).

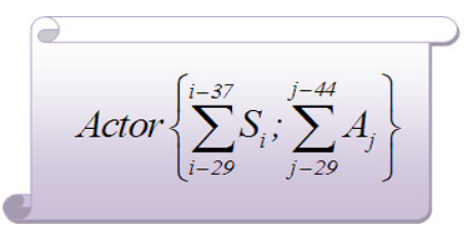

Figure 6. The model is then obtained End of University Cycle

The application Model is to justify the balance between all the activities of all actors and their aggregations at the 
end of a graduate level.

In this context (Figure 7) and in order to better appreciate this approach (Oubedda, Erraha, \& Khalfaoui, 2012c; Oubedda, Mir, \& Khalfaoui, 2009), we use a graphic presentation so as to show the equilibrium relationship between each actor and their activities at an undergraduate level and its aggregations. We take into account this multiple observation in order to develop our graphic model. It results that we can help via anticipation every identified actor by suggesting for him supplementary information which would help him to improve his outcomes.

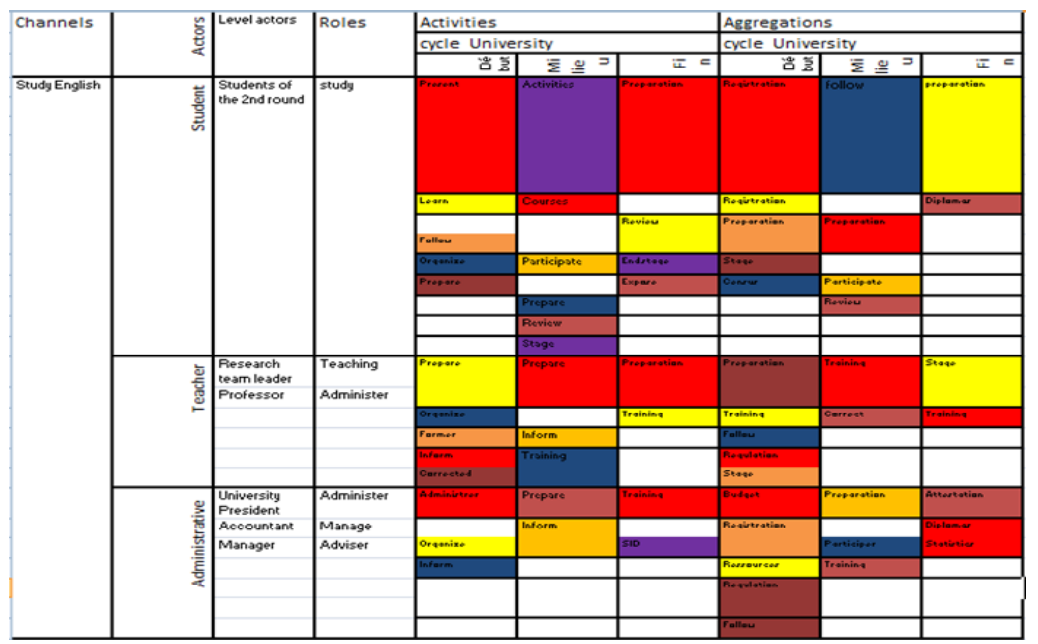

Figure 7. Model of application is to justify the balance between all the activities of all actors and their aggregations at the end of a graduate level

\subsubsection{The Dashboard Conception Method}

We adopt the GIMS method (Samia, Abdelghafour, \& Kinza, 2010; Thiery, Ducreau, Bouaka, \& David, 2004). This approach is intended to guide the system designer performance measurement as a phasing sequence. By proposing to follow the footsteps of the method, the actor wants to encourage the university to think in terms of strategy and objectives before proceeding to the implementation of a performance measurement system. In addition, the indicators must be constructed and selected taking into account not only the goals of the university, but also the activities and aggregations of each player during a university cycle. At all costs, the designer of the process should avoid the dashboard reduction to a predetermined set of synthetic indicators. The process is divided into 10 stages, each covering a particular concern and each marking an identifiable threshold in the system advancement (Figure 8).



Figure 8 . The steps can be grouped into four main phases 


\subsubsection{Background to Our Approach}

Construction of a multidimensional conceptual model (Bouaka \& David, 2003): We use the UML to model the types of actors (teacher, student, and administrator). Indeed, UML has a graphical notation as a visual based diagram that can facilitate decision making.

\section{Application}

After explaining the improvement of our model we use an open source product to make our application around a decision tree. We operate our business model around an application that gives us the opportunity to synthesize what we say and the challenge of using open source software that offers innovative perspectives on the treatment of information content as it is based on patterns XMLA for the analysis of data. We apprehend this new analysis model for our application which is discussed a development language allowing the manipulation of databases by MDX requests for analysis.

Our application described in Figure 9 revolves around two components: data recovery and retrieval of external data internally. Data recovery external offers pre-computed analyzes. Data recovery in house allows dynamic analysis of the real needs of schools and their aggregations.

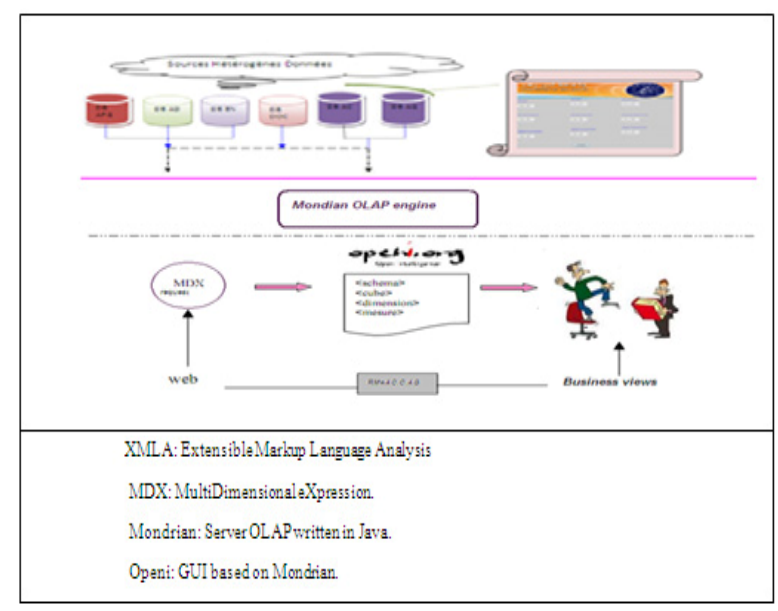

Figure 9. Revolves around two components: data recovery and retrieval of external data internall

Data recovery for external files "log" of the platform sub-ontology defined "needs", "functions" and "categories" are instantiated in advance to provide instances of players they will need when annotation of the document. We recover data and also build a bibliometric analysis around an information system to provide a decision analysis in a web interface and remote. The first part helps explain Mondrian.

Recovering data from our internal model (SIAG) and allows the identification of needs, functions and activities by type of actors in an information system dedicated to the decision of the academic environment. This second component is an integral part of Openi.

The internal and external data collected and analyzed lead to business views by type of actor.

\section{Conclusion}

To implement this application, we went through three main phases. The first is the theoretical part that needs to have a model that is able to respond in an academic setting known for its complexity (different actors, the wealth of data, non-uniform data ...).

This requires a mathematical model defining simple relationships between the actors, their activities and their aggregations. The second phase focuses on collecting data and designing a multi-dimensional. The third used as 'data about data', or reference data in the context of data aggregation and facilitate cross-analyzes. These Meta data (accessibility) used to describe the data used in analysis and decision making as the exact definition of the data (semantics), the source data (date, origin), how they are calculated, aggregated (calculation rules), business rules relating thereto, the process of extraction, transformation and loading that has been implemented (ETL). In the case of intelligence, so there are tools for extracting and managing Meta data that are so flexible - that is to say, scalable - and play an important role in the establishment. 
Data within data warehouses must be good quality, clean, but also described by Meta data to be managed best by the Management System Database to provide the most relevant results possible.

\section{References}

Ann, C. (2000). The data grid: Towards architecture for the distributed management and analysis of large scientific datasets. Journal of Network and Computer Applications, 23(3), 187-200. http://dx.doi.org/10.1006/jnca.2000.0110

Bouaka, N., \& David, A. (2003). Model for the operation of a decision problem: a tool for decision support in a context of economic intelligence. IERA 2003, Nancy.

Olivier, B. (2007a). Methods and tools for designing business process training systems. University Paul Verlaine-Metz.

Olivier, B. (2007b). Thiband Monteiro, Claude Pourcel, "Process modeling of a training system”. Proceedings 1st International Conference on Systems Engineering Training, October 2007, the Andes Cartagena, Colombia.

Oubedda, L., Erraha, A., \& Khalfaoui, M. (2012a). Tools for decision support in planning academic needs of actors. IJCSI International Journal of Computer Science Issues, 9(1).

Oubedda, L., Erraha, A., \& Khalfaoui, M. (2012b). Decision-making application for the Management of Human Resources: the automation of the recruitment to the breasts of Universities. IJCSI International Journal of Computer Science Issues, 9(2).

Oubedda, L., Erraha, A., \& Khalfaoui, M. (2012c). Conceptual modeling in the ontological basis of a Data Warehouse - Environment University. IJCSIS International Journal of Computer Science and Information Security, 10(2).

Oubedda, L., Mir, A., \& Khalfaoui, M. (2009). Human resource management of breast Moroccan Universities. ENCG AGADIR 2009.

Peguiron, F., David, A., Thiery, O. (2003). Intelligence in academic settings including the user modeling. IERA 2003, Nancy.

Samia, A., Abdelghafour K., \& Kinza, M. (2010). Proposal of a support decision support using the method gimsi, for better reactivity in a disturbed environment. International Conference On Industrial Engineering and Manufacturing ICIEM'10, May, 9-10, 2010, Banta, Algeria.

Thiery, O., Ducreau, A., Bouaka N., \& David, A. (2004). Drive an organization: strategic information to the modeling of the user application to the field of HRM. GREFIGE, 2004. 